\title{
MYCOLOGICAL PATTERN OF DERMATOMYCOSES IN A TERTIARY CARE CENTRE IN NORTH EAST INDIA
}

Urvashi Chongtham 1 , Gurumayum Preeti2, Huidrom Lokhendro Singh ${ }^{3}$

${ }_{1}^{1}$ Associate Professor, Department of Microbiology, JNIMS, Imphal, Manipur.

${ }^{2}$ Demonstrator, Department of Microbiology, JNIMS, Imphal, Manipur.

3Professor and HOD, Department of Microbiology, JNIMS, Imphal, Manipur.

\section{BACKGROUND}

ABSTRACT

Dermatomycoses constitute more than $50 \%$ of cases in Dermatology outpatient department, which do not require compulsory notifications, but rather cause cosmetic defacements. Indian subcontinent is favourable for various fungal infections. The objective of this study is to identify the aetiology of fungal infections of skin, nail and hair in patients attending tertiary care centre in north east India.

\section{MATERIALS AND METHODS}

A total of 160 samples from clinically suspected dermatomycoses were collected. Direct microscopy in 10\% KOH (potassium hydroxide) and culture on (Sabouraud's dextrose agar) SDA containing gentamicin (5 gm/L) and chloramphenicol (50 gm/L) were performed.

\section{RESULTS}

Out of the 160 samples, 95 cases were positive on direct KOH mount and 108 were culture positive. In 64 cases, both KOH and culture were positive. Maximum number of cases belonged to the age group of 31 - 40 years. Males were more affected compared to females. Most common isolates obtained in our study were yeasts followed by dermatophytes and non-dermatophytic moulds (NDMs). Candida albicans (25\%) was the most common yeast isolated. Among the dermatophytes, Trichophyton mentagrophytes was the commonest and among the non-dermatophytic moulds (NDMs), Aspergillus niger was the most frequent.

\section{CONCLUSION}

Our study reflects an increasing role of yeasts as a causative agent of dermatomycoses replacing the dermatophytes.

\section{KEYWORDS}

Dermatomycoses, Dermatophytes, Yeasts, Non-Dermatophytic Moulds.

HOW TO CITE THIS ARTICLE: Chongtham U, Preeti G, Singh HL. Mycological pattern of dermatomycoses in a tertiary care centre in North East India. J. Evolution Med. Dent. Sci. 2018;7(11):1373-1375, DOI: 10.14260/jemds/2018/312

\section{BACKGROUND}

Dermatophytes are a group of closely related fungi capable of invading keratinised tissues such as the skin, hair and nails causing infections referred to as dermatophytosis. Epidemiological studies showed that this pathology is among the most prevalent in the world and is considered the second most common skin disease in the adult population. It is estimated that $10 \%-15 \%$ of the general population may be affected by these microorganisms at some time in their lives. ${ }^{1}$

Dermatophytic infections are of major importance, as they are widespread and cause discomfort and aesthetic problems. Reactions to dermatophyte infection may range from mild to severe. The severity depend on a variety of factors such as the host reactions to the metabolic products of the fungus, the virulence of infecting species or particular strain, anatomical location of the infection and local environmental factors. ${ }^{1}$

Dermatophytic infections are a common clinical problem encountered in more than $50 \%$ of patients attending the

'Financial or Other Competing Interest': None.

Submission 02-02-2018, Peer Review 28-02-2018,

Acceptance 05-03-2018, Published 12-03-2018.

Corresponding Author:

Gurumayum Preeti,

Keishampat, Keisham Leikai,

Imphal West, Manipur.

E-mail: preetigurumayum@gmail.com

DOI: $10.14260 /$ jemds $/ 2018 / 312$

\section{(c) $(1)$}

dermatology outpatient departments. Overcrowding, poor hygiene, low standards of living along with high humidity environments are contributing to the increased prevalence of these fungal infections. The present study was conducted to know the prevalence and aetiology of dermatomycoses involving skin, hair and nail.2

Trichophyton, Microsporum and Epidermophyton are the genera implicated to cause dermatophytoses. These dermatophytes are closely related filamentous fungi and cause the disease by virtue of their unique ability to degrade keratin and invade the skin and its appendages. ${ }^{2}$ Other than dermatophytes, there has been an increased role of NDMs like A. niger, A. flavus, Penicillium etc. and yeasts like C. albicans, non-albicans Candida as the causative agents of dermatomycoses. ${ }^{3}$

\section{MATERIALS AND METHODS}

A total of 160 samples from clinically suspected dermatomycoses attending a tertiary care centre in north east India during a period of 1 year from Sept'16 - Sept'17 were registered. Infants and patients who had undergone antifungal treatment in the previous one month were excluded from the study.

\section{Collection of Samples}

Samples were collected after cleaning the affected surface with $70 \%$ alcohol. From skin lesions, scales were collected 
from erythematous growing margins of the lesion with a sterile blunt scalpel and in case of tinea capitis, infected and lustreless hairs were plucked with sterile surgical forceps. In tinea unguium, nail clippings were taken. Samples were collected in sterilised Whatman filter paper envelope as fungal spores resist drying and remain viable for several weeks when stored in paper.

\section{Direct Microscopic Examination}

Direct examination of fungal elements from skin scales and hair samples was done by using $10 \% \mathrm{KOH}$ mounts.

\section{Isolation by Culture}

All the samples were cultured on Sabouraud's dextrose agar (SDA) with gentamicin (5 gm/L) and chloramphenicol (50 $\mathrm{gm} / \mathrm{L}$ ). Samples were inoculated in two sets of the culture media. One set was incubated at $37^{\circ} \mathrm{C}$ and another set at $25^{\circ} \mathrm{C}$. Cultures were examined thrice weekly for the appearance of growth. Cultures were incubated for 1-month before discarding them as negative. Fungal growth was identified by colony morphology, pigment production and microscopic examination by tease mount technique in lactophenol cotton blue (LPCB). Urease test and in-vitro hair perforation tests were also performed to differentiate Trichophyton rubrum and Trichophyton mentagrophytes when there was difficulty in identification by microscopic and macroscopic examination.

Cream coloured, smooth looking colonies were subjected to Gram stain. Colonies showing Gram positive budding yeast like cells with pseudohyphae were further subjected to germ tube test.

\section{RESULTS}

Out of the 160 cases, majority of them belonged to the age group of 31 - 40 years $(40 ; 25 \%)$ followed by 21 - 40 years (35; 21\%). The youngest patient was a 7-year-old boy and the eldest was an 81-year-old man [Table 1]. 91 (57\%) of the samples belonged to males and $69(43 \%)$ were female with a male: female ratio of 1.3: 1 [Table 2].

Out of all the samples received 80 were nail, 67 were skin and 13 were hair [Table 3]. Among the 160 samples, 95 cases were positive on direct $\mathrm{KOH}$ mount and 108 were culture positives. In 64 cases, both $\mathrm{KOH}$ and culture were positive. 77 (48\%) of the samples were both $\mathrm{KOH}$ and culture negative, [Table 4].

Most common isolates obtained in our study were yeasts $(42,38.8 \%)$ followed by dermatophytes $(37,34 \%)$ and NDMs $(29,26.8 \%)$. Among the yeasts, C. albicans $(27,25 \%)$ was the commonest followed by non-albicans Candida $(15,13.8 \%)$. Among the dermatophytes, T. mentagrophytes (15, 13.8\%) was the commonest followed by $\mathrm{T}$. rubrum $(12,11 \%), \mathrm{T}$. verrucosum $(6,5.5 \%)$, T. tonsurans $(3,2.7 \%)$ and M. gypseum (1\%). Among the NDMs, A. niger was the most common (5, $4.6 \%$ ) followed by Fusarium spp. (4, 3.7\%), Cladosporium spp. (2, 1.8\%), Exophiala dermatitidis $(3,2.7 \%)$, Penicillium marneffei $(3,2.7 \%)$, Scopulariopsis spp. $(3,2.7 \%)$, Aspergillus flavus $(2,1.8 \%)$, Aspergillus fumigatus $(2,1.8 \%)$, Cladosporium carrionii $(4,3.7 \%)$, Cladophialophora spp. (2, $1.8 \%)$ and Geotrichum spp. (1, 1\%) [Table 5].

\begin{tabular}{|c|c|}
\hline Age Groups & No. of Patients \\
\hline $0-10$ & 6 \\
\hline $11-20$ & 18 \\
\hline $21-30$ & 35 \\
\hline $31-40$ & 40 \\
\hline $41-50$ & 27 \\
\hline $51-60$ & 23 \\
\hline$>61$ & 11 \\
\hline Total & 160 \\
\hline \multicolumn{2}{|c|}{ Table 1. Age Distribution of Patients } \\
\hline
\end{tabular}

\begin{tabular}{|c|c|c|}
\hline Males & Females & Male: Female Ratio \\
\hline $91(57 \%)$ & $69(43 \%)$ & $1.3: 1$ \\
\hline \multicolumn{3}{|c|}{ Table 2. Gender Distribution of Patients } \\
\hline
\end{tabular}

\begin{tabular}{|c|c|}
\hline Skin & 67 \\
\hline Hair & 13 \\
\hline Nail & 80 \\
\hline Total & $\mathbf{1 6 0}$ \\
\hline Table 3. Total Samples received in the Laboratory \\
\hline
\end{tabular}

\begin{tabular}{|c|c|c|c|c|}
\hline Samples & $\begin{array}{c}\text { Total } \\
\text { KOH + }\end{array}$ & $\begin{array}{c}\text { Total } \\
\text { Culture + }\end{array}$ & Both + & Both - \\
\hline Skin (n=67) & $37(55 \%)$ & $44(65 \%)$ & $27(40 \%)$ & $30(45 \%)$ \\
\hline Hair (n=13) & $5(38 \%)$ & $7(53 \%)$ & $5(38 \%)$ & $5(41 \%)$ \\
\hline Nail (n=80) & $53(66 \%)$ & $57(71 \%)$ & $32(40 \%)$ & $42(53 \%)$ \\
\hline $\begin{array}{c}\text { Total } \\
(\mathrm{n}=160)\end{array}$ & $\mathbf{9 5 ( 5 9 \% )}$ & $\mathbf{1 0 8}(\mathbf{6 7 \% )}$ & $\mathbf{6 4}(\mathbf{4 0 \% )})$ & $\mathbf{7 7}(\mathbf{4 8 \% )}$ \\
\hline \multicolumn{4}{|c|}{ Table 4. Correlation between Sample Type, } \\
KOH and Culture \\
\hline
\end{tabular}

\begin{tabular}{|c|c|c|}
\hline & Organisms & $\begin{array}{c}\text { Number of } \\
\text { Isolates (\%) }\end{array}$ \\
\hline \multirow{2}{*}{$\begin{array}{l}\text { Yeasts } \\
(38.8 \%)\end{array}$} & 1. Candida albicans & $27(25 \%)$ \\
\hline & Non-albicans candida & $15(13.8 \%)$ \\
\hline \multirow{5}{*}{$\begin{array}{c}\text { Dermatophytes } \\
(34 \%)\end{array}$} & 3. $\quad$ T. mentagrophytes & $15(13.8 \%)$ \\
\hline & 4. T. rubrum & $12(11 \%)$ \\
\hline & 5. T. verrucosum & $6(5.5 \%)$ \\
\hline & 6. T. tonsurans & $3(2.7 \%)$ \\
\hline & 7. Microsporum gypseum & $1(1 \%)$ \\
\hline \multirow{9}{*}{$\begin{array}{c}\text { Non- } \\
\text { dermatophytic } \\
\text { Moulds /NDM } \\
(26.8 \%)\end{array}$} & 8. A. niger & $5(4.6 \%)$ \\
\hline & 9. $\quad$ Fusarium spp. & $4(3.7 \%)$ \\
\hline & 10. C. carrionii & $4(3.7 \%)$ \\
\hline & 11. E. dermatitidis & $3(2.7 \%)$ \\
\hline & 12. P.marneffei & $3(2.7 \%)$ \\
\hline & 13. Scopulariopsis spp. & $3(2.7 \%)$ \\
\hline & 14. Cladophialophora spp. & $2(1.8 \%)$ \\
\hline & 15. A. fumigatus & $2(1.8 \%)$ \\
\hline & 16. Geotrichum spp. & $1(1 \%)$ \\
\hline Total & & 108 \\
\hline
\end{tabular}

\section{DISCUSSION}

The reason for increased percentage of males may be due to increased outdoor exposure and more physical work that results in increased sweating. This finding is similar to that of earlier studies. 2,4,5 However, in a study done in northern Iran by Falahi AA and his colleagues published at 2017 showed a female preponderance. ${ }^{6}$

It is also found that the dermatophyte infection is predominant in the adult age group (31 - 40 years). This may be due to increased level of physical activity in the particular age group leading to excessive sweating, which favours the growth of dermatophytes. Socialisation with different people is also high in this age group, which eventually helps in 
spreading of infection. This finding correlates with the earlier studies. $^{7}$

The predominant isolates obtained in our study were yeasts $(42,38.8 \%)$ followed by dermatophytes $(37,34 \%)$ and NDMs $(29,26.8 \%)$. Among the yeasts, C. albicans (25\%) was the commonest followed by non-albicans Candida (13.8\%). Among the dermatophytes, $\mathrm{T}$. mentagrophytes $(15,13.8 \%)$ was the commonest followed by $\mathrm{T}$. rubrum $(12,11 \%), \mathrm{T}$. verrucosum $(6,5.5 \%)$, T. tonsurans $(3,2.7 \%)$ and $M$. gypseum $(1,1 \%)$. Among the NDMs, A. niger was the most common (5, 4.6\%) followed by Fusarium spp. (4, 3.7\%), Cladosporium spp. (2, 1.8\%), Exophiala dermatitidis $(3,2.7 \%)$, Penicillium marneffei $(3,2.7 \%)$, Scopulariopsis spp. $(3,2.7 \%)$, Aspergillus flavus $(2,1.8 \%)$, Aspergillus fumigates $(2,1.8 \%)$, Cladosporium carrionii $(4,3.7 \%)$, Cladophialophora spp. (2, $1.8 \%)$ and Geotrichum spp. $(1,1 \%)$.

Many studies showed that dermatophytes were the most common fungi associated with dermatomycoses. But in our study, the most frequently isolated organism was found to be yeasts- Candida spp. (38.8\%). It may be due to the fact that majority of the samples received were nails and yeast is one of the commonest causative agents of onychomycosis. This finding is in accordance with the studies conducted at Mumbai and Gujarat.5,8

\section{CONCLUSION}

Most common isolates obtained in our study were yeasts followed by dermatophytes and NDMs. Our study reflects an increasing role of yeasts as a causative agent of dermatomycoses, replacing the dermatophytes. As treatment protocol differs depending upon the causative agents of dermatomycoses, culture identification is a must.

\section{REFERENCES}

[1] Magagnin CM, Stopiglia CD, Vieira FJ, et al. Antifungal susceptibility of dermatophytes isolated from patients with chronic renal failure. An Bras Dermatol 2011;86(4):694-701.

[2] Poluri LV, Indugula JP, Kondapaneni SL. Clinicomycological study of dermatophytosis in south India. J Lab Physiscians 2015;7(2):84-9.

[3] Kaur R, Panda PS, Sardana K, et al. Mycological pattern of dermatomycoses in a tertiary care hospital. Article ID 157828, Journal of Tropical Medicine 2015;2015: p. 5.

[4] Surendran KAK, Bhat RM, Boloor R, et al. A clinical and mycological study of dermatophytic infections. Indian J Dermatol 2014;59(3):262-7.

[5] Suryawanshi RS, Wanjare SW, Koticha AH, et al. Onychomycois: dermatophytes to yeasts: an experience in and around Mumbai, Maharashtra, India. Int J Res Med Sci 2017;5(5):1959-63.

[6] Falahi AA, Rezaei-Matehkolaei A, Rezaei S. Epidemiological status of dermatophytosis in Guilan, North Iran. Curr Med Mycol 2017;3(1):20-4.

[7] Janardhan B, Vani G. Clinicomycological status of dermatophytosis. Int J Res Med Sci 2017;5(1):1-9.

[8] Gelotar P, Vachhani S, Patel B, et al. The prevalence of fungi in fingernail onychomycosis. Journal of Clinical and Diagnostic Research 2013;7(2):250-2. 